\title{
Archipel
}

ARCHIPEL Études interdisciplinaires sur le monde insulindien

Hors-Série $n^{\circ} 1$ - Ge SONG, Indes néerlandaises et culture chinoise - Deux traductions malaises du Roman des Trois Royaumes (1910-1913) | 2021

Ge SONG, Indes néerlandaises et culture chinoise Deux traductions malaises du Roman des Trois Royaumes (1910-1913)

\section{Liste des illustrations hors-texte extraites du Sam Kok de Tjie Tjin Koeij}

\section{OpenEdition}

\section{Journals}

Édition électronique

URL : https://journals.openedition.org/archipel/2550

DOI : 10.4000/archipel.2550

ISSN : 2104-3655

Éditeur

Association Archipel

Édition imprimée

Date de publication : 29 novembre 2021

Pagination : vii

ISBN : 978-2-910513-86-3

ISSN : 0044-8613

Référence électronique

« Liste des illustrations hors-texte extraites du Sam Kok de Tjie Tjin Koeij », Archipel [En ligne], HorsSérie $n^{\circ} 1$ - Ge SONG, Indes néerlandaises et culture chinoise - Deux traductions malaises du Roman des Trois Royaumes (1910-1913) | 2021, mis en ligne le 06 décembre 2021, consulté le 16 mars 2022. URL : http://journals.openedition.org/archipel/2550 ; DOI : https://doi.org/10.4000/archipel.2550

Ce document a été généré automatiquement le 16 mars 2022.

Association Archipel 


\section{Liste des illustrations hors-texte extraites du Sam Kok de Tjie Tjin Koeij}

1. Portrait de Liu Bei, Guan Yu et Zhang Fei

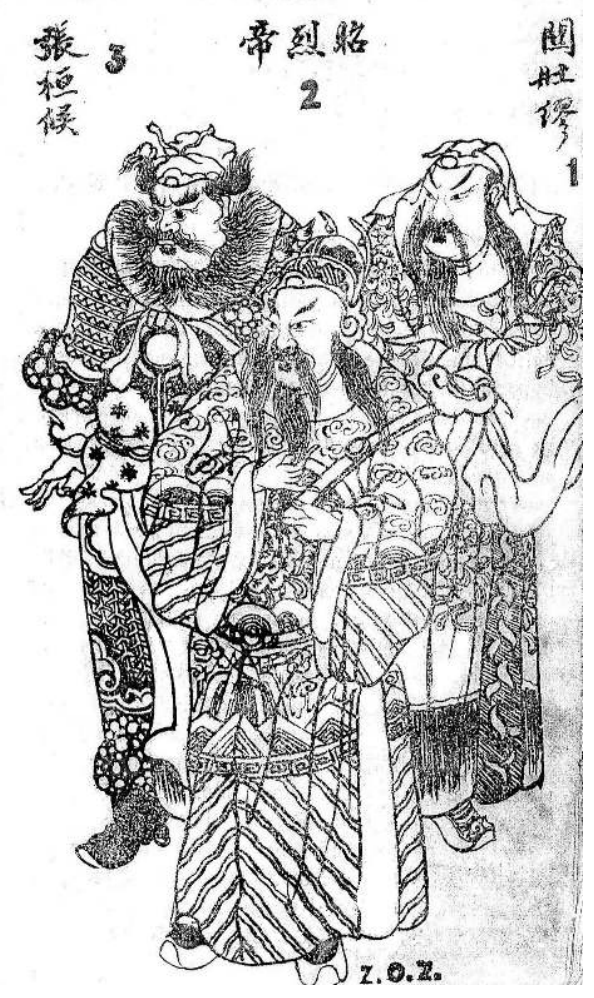


2. « Trois valeureux héros jurent fraternité dans le jardin des Pêchers. » Chapitre. 1 (de l'original)

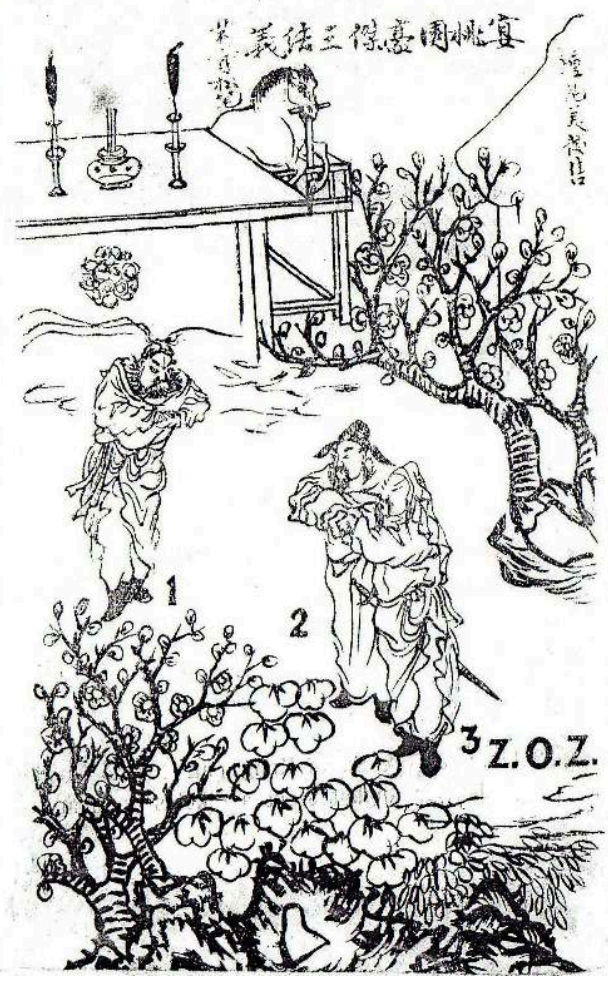

3. Portrait de Dong Zhuo, Lü Bu et Diao Chan

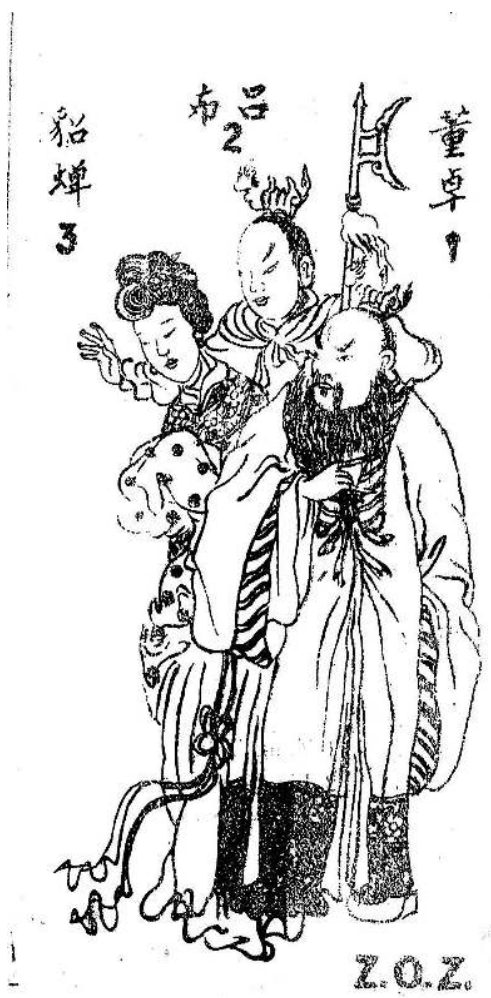

Archipel, Hors-Série $n^{\circ} 1$ - Ge SONG, Indes néerlandaises et culture chinoise - Deux traductions malaises du Roman des Trois Royaumes (1910-1913) | 2021 
4. «Trois braves, Liu Bei, Guangong et Zhang Fei combattent Lü Bu à la passe de Hulao. » Chap. 5

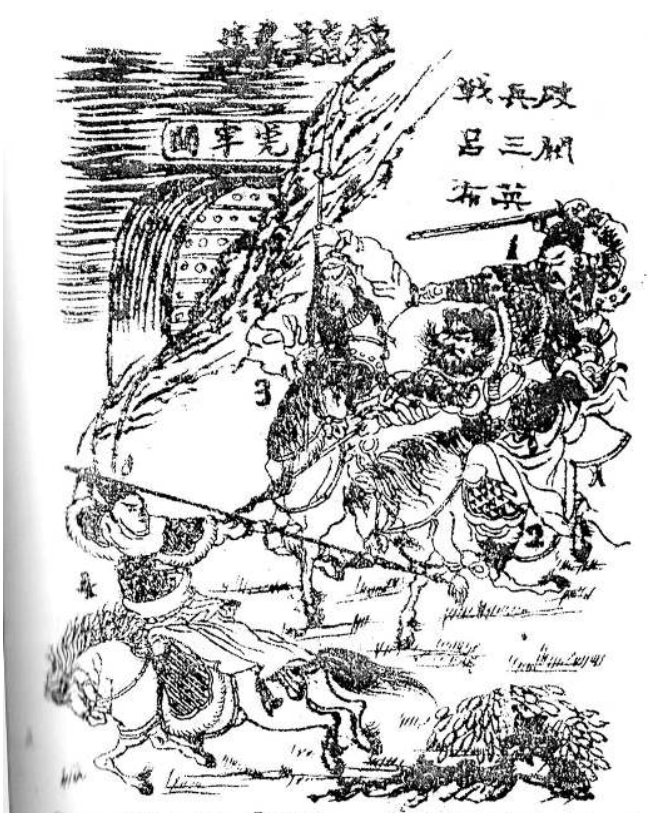

Sam Tjian Lje Pouw. - Didepan kota Houw

Kwan, tigg orang gagah, jaitoe: Lauw Pie (1) kwan Kong (2) dan Thio Hoeij (3) telah berpe ang keroebocti Lie Pouw (4)

5. « Stratagèmes en chaîne de Wang Yun ». Chap. 8

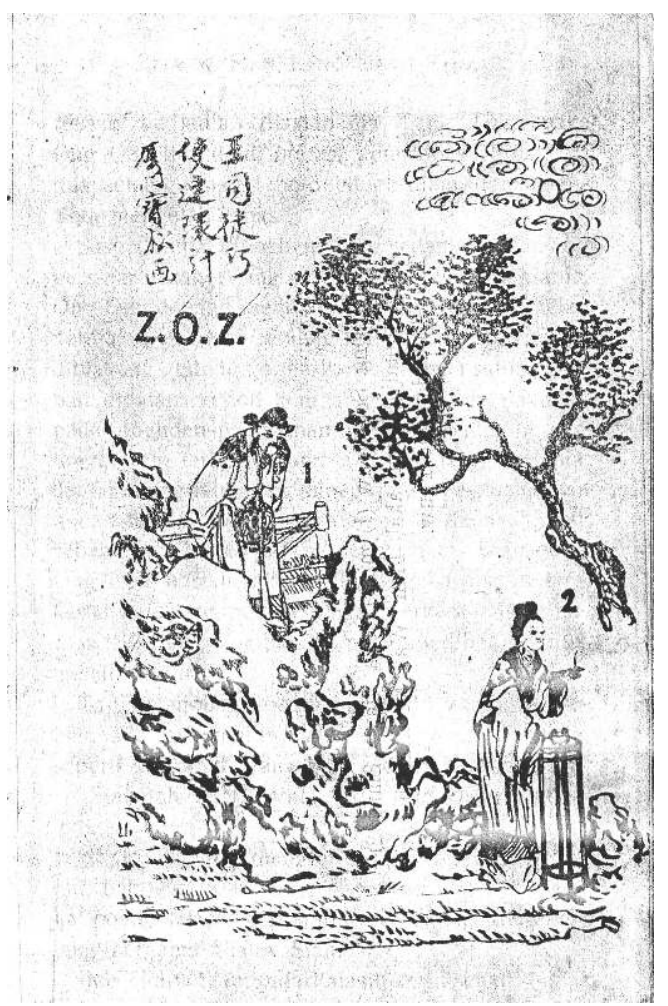

Archipel, Hors-Série $n^{\circ} 1$ - Ge SONG, Indes néerlandaises et culture chinoise - Deux traductions malaises du Roman des Trois Royaumes (1910-1913) | 2021 
6. Portrait de Zhou Cang et deux personnages dont les noms ne sont pas lisibles.

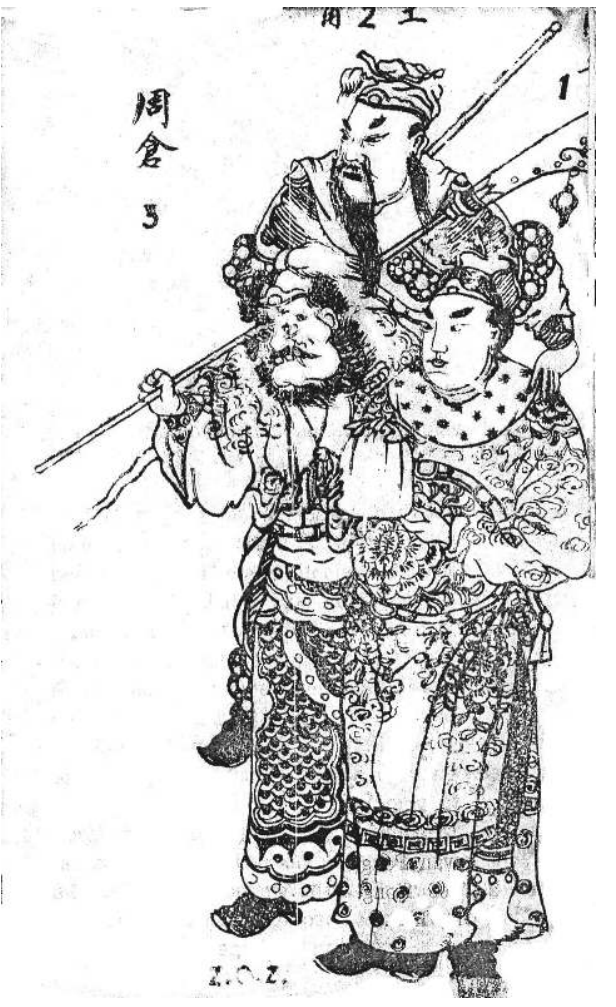

7. Portrait de Lu Su, Jiang Gan et Zhou Yu.

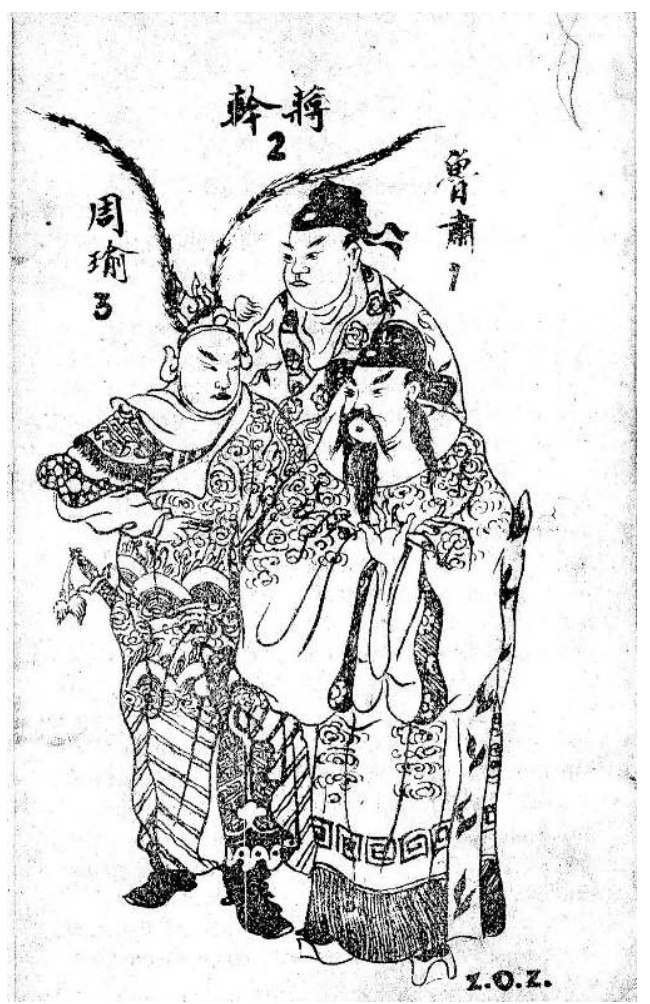


8. "Guangong tue Cai Yang afin que Zhang Fei ne soit plus méfiant. » Chap. 28

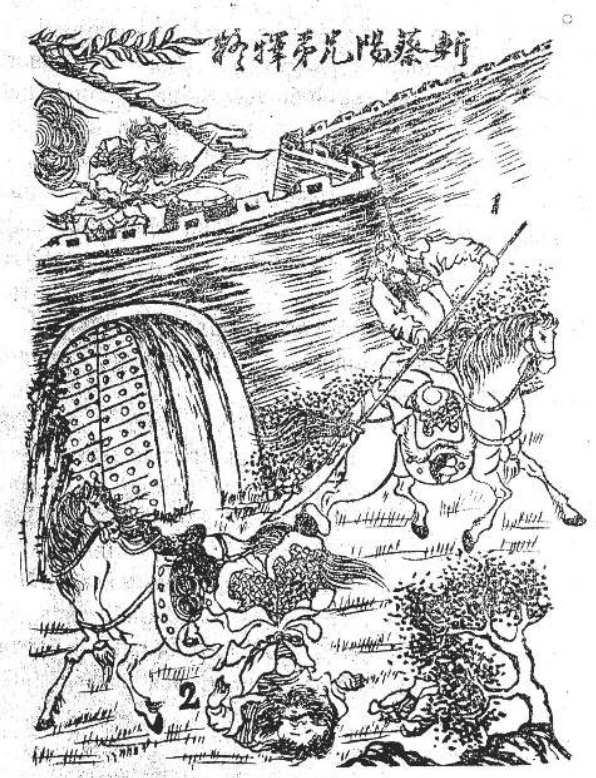

Kwan Kong (1) toenoeh Tjoa Jong (2) aken nembikin litang tjoeriga tratinja Thio Hoeij (B).

9. « Image montrant Liu Bei invitant Kongming qui décide que le pays sera divisé en trois. Ce qui est montré du doigt par Kongming est la carte de l'État de Shu 蜀 (Sichuan 四川). »Chap. 38

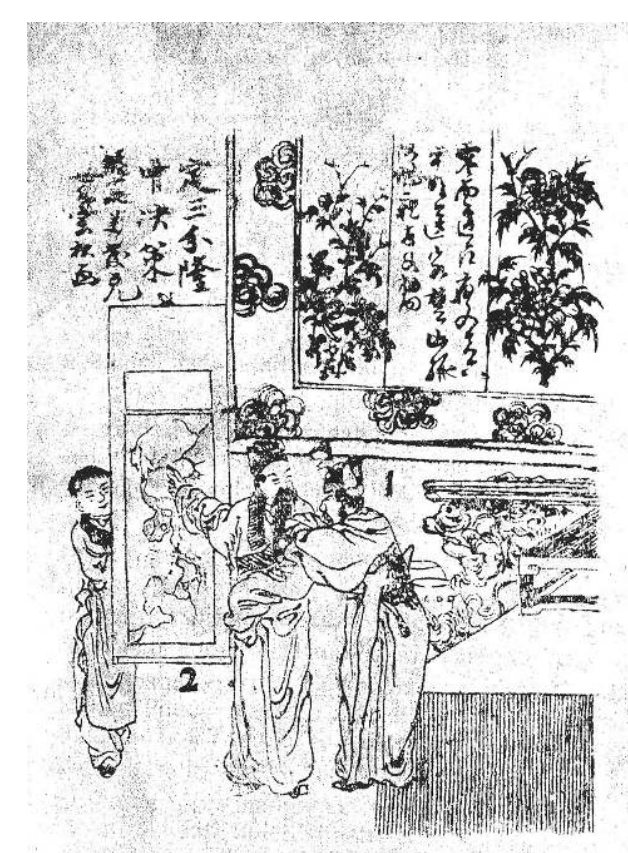

Bi ini gambar ada kelikatan laau Pie (1) sedang mengoendses Kong Batg (2) - Kong Beng

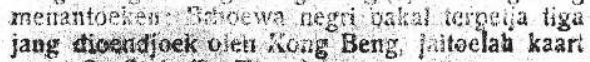
negri Se Siok (Se Tjpan) 
10. « Kongming affronte en paroles les fonctionnaires de Sun Quan, souverain de l'État de Dongwu 東吳. » Chap. 43

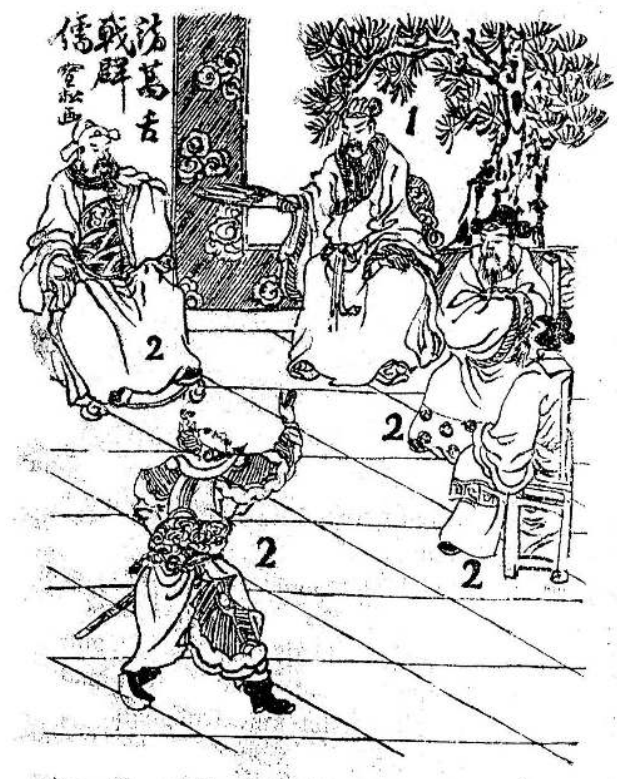

Kong Beng (1) sedang adoeh bitjara pada sekalian penggawenja Soen Kwar di Tong Gouw(2)

11. « Cette image montre Kongming (en fait Guangong) en train de promettre à Guangong (en fait Kongming) qu'il doit aller arrêter Cao Cao. Kongming est sûr que Cao Cao va s'enfuir par le sentier de Huarong. » Chap. 50

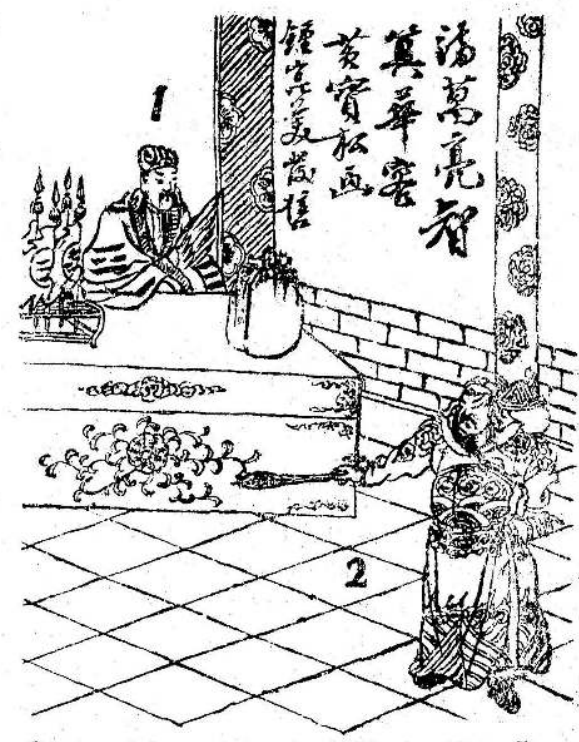

Qstain ini gambar ada kelihatan Kong Beng scuang bikin soezat perdjandilan pada $K r$ Kaf (3) jang misti pergi menjegat Tjo Tjoh. Kong Beng menantoeken Bshoewa Tjo Tj misti lari ambil djalan dari strat Hoa ljong 
12. « Cao Cao organise une grande fête dans le palais Tongque tai pour tous les héros et les fonctionnaires. »Chap. 56

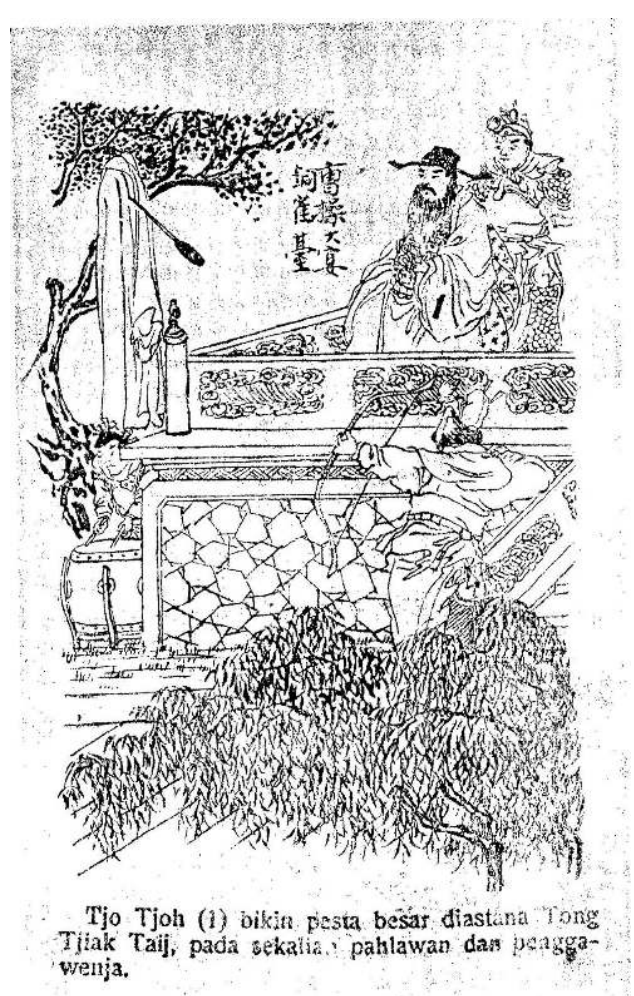

13. Portrait de l'Impératrice Cao, en compagnie de Hua Xin et Sima Yan.

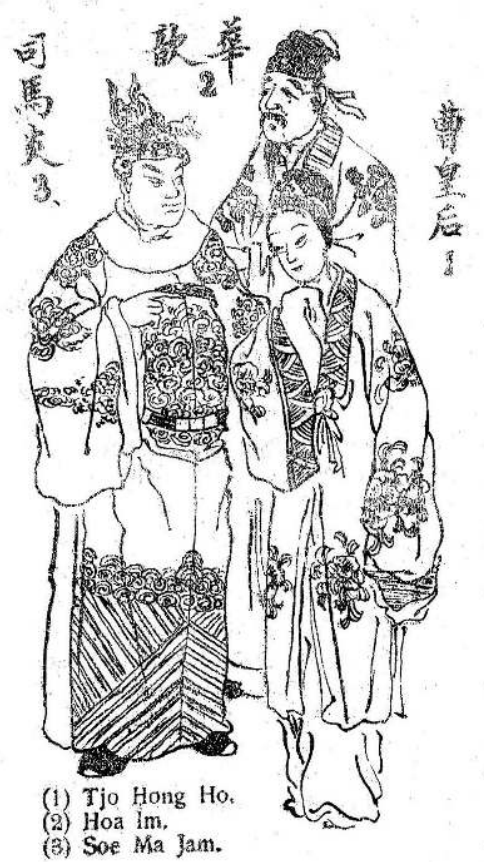

Archipel, Hors-Série $n^{\circ} 1$ - Ge SONG, Indes néerlandaises et culture chinoise - Deux traductions malaises du Roman des Trois Royaumes (1910-1913) | 2021 
14. " Après la reddition de l'Empereur Sun Hao de Wu, les Trois Royaumes sont de nouveau réunis et [dirigés par] Sima Yan (descendant de Sima Yi). » Chap. 120

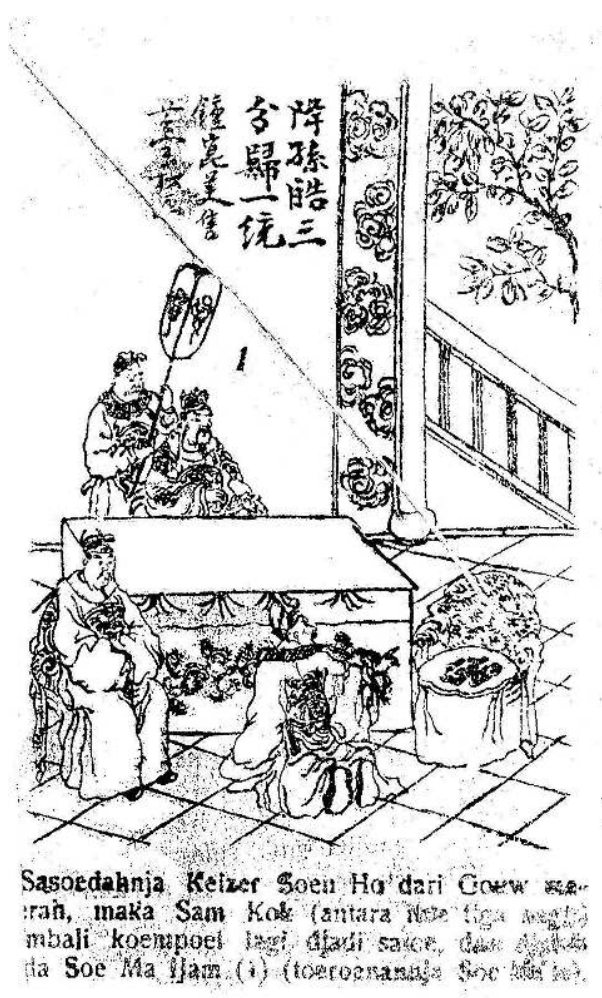

1 Illustrations reproduites et choisies par Lie Limei que nous remercions ici. Celles-ci ne constituent qu'une petite partie des illustrations du Sam Kok de Tjie Tjin Koeij. Elles sont par ailleurs très rares dans les versions numériques des Sam Kok du KITLV. 